\title{
Treadmill Exercise Ameliorates Short-term Memory Impairment by Suppressing Hippocampal Neuroinflammation in Poloxamer- 407-Induced Hyperlipidemia Rats
}

\author{
Sang-Seo Park ${ }^{1,2}$, Tae-Woon Kim³ ${ }^{3}$, Yun-Hee Sung ${ }^{4}$, Yun-Jin Park ${ }^{5}$, Myung-Ki Kim ${ }^{6}$, Mal-Soon Shin ${ }^{6}$ \\ ${ }^{1}$ Department of Physiology, College of Medicine, Kyung Hee University, Seoul, Korea \\ ${ }^{2}$ School of Health and Kinesiology, University of Nebraska at Omaha, Omaha, NE, USA \\ ${ }^{3}$ Department of Human Health Care, Gyeongnam National University, Jinju, Korea \\ ${ }^{4}$ Department of Physical Therapy, College of Health Sciences, Kyungnam University, Changwon, Korea \\ ${ }^{5}$ Department of Health Rehabilitation, Osan University, Osan, Korea \\ ${ }^{6}$ College of Culture and Sports, Division of Global Sport Studies, Korea University, Sejong, Korea
}

Purpose: Poloxamer-407 (P-407) is used to induce hyperlipidemia. Exercise is effective in improving arteriosclerosis and cognitive impairment. In this research, the effect of treadmill running on short-term memory in the P-407-treated hyperlipidemia rats was studied focusing on neuroinflammation.

Methods: Rats were classified in normal group, normal and treadmill exercise group, P-407-treated group, and P-407-treated and treadmill exercise group. Hyperlipidemia rats were made by single intraperitoneal injection with P-407 (500 mg/kg). Treadmill exercise was conducted for 30 minutes once a day, 5 days per week during 28 days. Step-down avoidance task was done to measure short-term memory. Glial fibrillary acidic protein and ionized calcium binding adaptor molecule 1 were assessed by immunohistochemistry. Expression of adhesion molecules and proinflammatory cytokines was determined by western blot analysis.

Results: Treadmill exercise alleviated lipid profiles in the P-407-induced hyperlipidemia rats. Treadmill exercise improved short-term memory, inhibited reactive astrogliosis and microglia activation, and suppressed expression of adhesion molecules and proinflammatory cytokines in the hyperlipidemic rats.

Conclusions: Treadmill exercise exerts alleviating effect on memory deficits by inhibiting hippocampal neuroinflammation in the hyperlipidemia. The current results suggest that treadmill running serves as the treatment strategy for the cognitive dysfunction caused by hyperlipidemia.

Keywords: Hyperlipidemia; Treadmill exercise; Glial fibrillary acidic protein; Ionized calcium binding adaptor molecules 1; Adhesion molecules; Proinflammatory cytokines

- Fund/Grant Support: This work was supported by the Ministry of Education of the Republic of Korea and the National Research Foundation of Korea (NRF-2019R1F1A1059084).

- Research Ethics: The approval number of KHUASP (SE)-18-047 was obtained from the Institutional Animal Care and Use Committee of Kyung Hee University for this experiment.

- Conflict of Interest: No potential conflict of interest relevant to this article was reported.

\footnotetext{
- HIGHLIGHTS

- Injection of poloxamer-407 induced hyperlipidemia and impaired short-term memory.

- Treadmill running improved short-term memory deficits in the hyperlipidemia rats.

-Treadmill running inhibited hippocampal neuroinflammation in the hyperlipidemia rats.
}

Corresponding author: Mal-Soon Shin (iD https://orcid.org/0000-0002-7462-2211 College of Culture and Sports, Division of Global Sport Studies, Korea University, 2511 Sejong-ro, Sejong 30019, Korea

Email: malsoon@korea.ac.kr

Submitted: September 15, 2021 / Accepted after revision: October 28, 2021
This is an Open Access article distributed under the terms of the Creative Commons Attribution Non-Commercial License (http://creativecommons.org/licenses/by-nc/4.0/) which permits unrestricted non-commercial use, distribution, and reproduction in any medium, provided the original work is properly cited. 


\section{INTRODUCTION}

Hyperlipidemia refers to a condition in which an excess of fat component is present in the blood and causes inflammation. Hyperlipidemia is diagnosed when fasting serum cholesterol level is greater than $220 \mathrm{mg} / \mathrm{dL}$ or triglyceride (TG) level is greater than $150 \mathrm{mg} / \mathrm{dL}$ [1]. Elevated blood lipids are known to be a major trigger for neurodegenerative diseases such as Alzheimer disease [2]. A single intraperitoneal injection of poloxamer-407 (P-407) induces a rapid onset of hyperlipidemia, which increases serum lipoprotein level by altering lipid metabolism and cholesterol biosynthesis by inhibiting lipoprotein lipase, which promotes hydrolysis of TG [3].

Astrocyte-related pathogenesis causes Alzheimer disease and Parkinson disease [4]. Glial fibrillary acidic protein (GFAP) is the main component of filaments of the cytoskeleton of astrocytes. GFAP was increased at the sites of forebrain ischemia areas with edema or neuronal damage [5]. Microglia in the central nervous system normally remain quiescent, but when activated, microglia can perform a variety of functions that may be beneficial or detrimental, depending on the situation [6]. The ionized calcium binding adapter molecule 1 (Iba-1) protein is a microglia and macrophage specific calcium binding protein. Activated microglia play an important role in immune-mediated neurodegenerative diseases [7]. Neutrophilia caused by hypercholesterolemia primarily invades arteries in the early stages of atherosclerosis [8]. Level of serum proinflammatory cytokines, such as tumor necrosis factor (TNF)- $\alpha$, interleukin (IL)6 , and IL- $1 \beta$, was elevated in hyperlipidemic patients with periodontitis [9].

Adhesion molecules in the vascular endothelium cause endothelial dysfunction and act as inducing factor of the atherosclerosis [10]. Vascular cell adhesion molecule (VCAM)-1 and intercellular adhesion molecule (ICAM)- 1 are expressed in the endothelial cell membrane and regulate adhesion of leucocytes and their migration to the endothelium of blood vessels [11]. VCAM-1 and ICAM-1 level was enhanced by increased expression of TNF- $\alpha$, IL-6, IL-1 $\beta$, and interferon (IFN)- $\gamma$ [12]. Interestingly, enhanced expression of VCAM-1 and ICAM- 1 in the Alzheimer dementia reflects morphologic change of white matter and impairment of short-term memory [13].

Exercise decreased serum level of TC and low-density lipoprotein cholesterol (LDL-C) and enhanced serum level of highdensity lipoprotein cholesterol (HDL-C) [14]. The improving effect on short-term memory and the increasing effect on cell proliferation and synaptic plasticity of the treadmill running in mice with photothrombotic stroke are well documented [15]. Nevertheless, the effect of treadmill running on memory deficits in the hyperlipidemia has not yet been elucidated.

Therefore, the effect of treadmill exercise on short-term memory deficits in the hyperlipidemia-induced rats caused by P-407 injection was studied, focusing on neuroinflammation. Serum lipid profiles were analyzed by automated analyzer and short-term memory was measured by step-down avoidance task. Immunohistochemistry for GFAP and Iba- 1 and Western blotting for VCAM-1, ICAM-1, TNF- $\alpha$, IL-6, and IL- $1 \beta$ were done.

\section{MATERIALS AND METHODS}

\section{Animals}

The approval number of KHUASP (SE)-18-047 was obtained from the Institutional Animal Care and Use Committee of Kyung Hee University for this experiment. Sprague-Dawley male adult rats (180-200 g in weight and 8-week old) were used for this study. Rats were classified into 4 groups ( $\mathrm{n}=10$ in each group): normal group, normal and treadmill exercise group, P-407treated group, and P-407-treated and treadmill exercise group.

\section{Treadmill Running Protocol}

The amount of treadmill running was performed for $30 \mathrm{~min}$ utes a day, 5 times a week for 28 days. The exercise protocol consisted of 3 sessions. According to the method of Ko et al. [16], rats ran on the treadmill at 0 degree of inclination at a speed of $3 \mathrm{~m} / \mathrm{min}$ for the first 5 minutes, $5 \mathrm{~m} / \mathrm{min}$ for the next 5 minutes, and $8 \mathrm{~m} / \mathrm{min}$ for the last 20 minutes.

\section{Induction of Hyperlipidemia}

After 28 days of treadmill exercise, for the induction of hyperlipidemia, 500-mg/kg P-407 (overnight in cold sterile $\mathrm{NaCl}$ $0.9 \%$ solution) was injected intraperitoneally one time, following the previously mentioned method [17]. The normal rats were injected same volume of $0.9 \% \mathrm{NaCl}$ solution.

\section{Measurement of Lipid Profile}

Blood sample was collected immediately from abdominal aorta and centrifugation at 3,000 rpm for 15 minutes was done. Serum was then isolated and stored at $-80^{\circ} \mathrm{C}$ until use. Serum level of TC, LDL-C, TG, and HDL-C was measured by the automatic analyzer (Hitachi, Tokyo, Japan). 


\section{Step-Down Avoidance Task}

The step-down avoidance task was used for the determination of short-term memory at 29 days after experiment starting, following the previously mentioned method [18]. Rats were put on the platform and as soon as it came down, 0.5-mA paw shock applied for 2 seconds. After 2 hours of the training session, latency time was measured, which was defined as the time the rats spend on the platform. A latency time exceeding 300 seconds was regard as 300 seconds.

\section{Tissue Preparation}

After anesthetizing the rats by diethyl ether (Sigma Aldrich Co., St. Louis, MO, USA), 50mM phosphate-buffered saline (PBS) and $4 \%$ paraformaldehyde in $100 \mathrm{mM}$ phosphate buffer $(\mathrm{pH}$, 7.4) were perfused through heart. After taking out the brain, the brain was treated with $4 \%$ paraformaldehyde at $4^{\circ} \mathrm{C}$ for overnight for fixation, and transferred in a 30\% sucrose for cyroprotection. Freezing microtome (Leica, Nussloch, Germany) was applied to make $40-\mu \mathrm{m}$-thick coronal sections.

\section{GFAP and lba-1 Immunohistochemistry}

Immunohistochemistry for GFAP and Iba-1 expression was used, following the previously mentioned method [19]. The sections were pretreated with $3 \% \mathrm{H}_{2} \mathrm{O}_{2}$ for 30 minutes, treated with PBS, and incubated with $10 \%$ blocking solution at room temperature. The sections were incubated with goat anti-GFAP antibody (1:500; Cell Signaling Technology, Danvers, MA, USA) and rabbit anti-Ibal antibody (1:500; Cell signaling Technology) at $4^{\circ} \mathrm{C}$ overnight. On the next day, the sections were treated with biotinylated secondary antibodies (1:200; Vector laboratories, Burlingame, CA, USA) against GFAP and Iba-1 for 2 hours, then the sections were treated with avidin-biotin peroxidase kit (1:100; Vector Laboratories) and $0.03 \%$ diaminobenzidine containing $0.03 \% \mathrm{H}_{2} \mathrm{O}_{2}$ at room temperature. The GFAP immunoreactivity was expressed as the optical density and Iba-1 immunoreactivity was presented as the number of Iba-1-positive cells/ $\mathrm{mm}^{2}$.

\section{Western Blot Analysis}

Western blotting was done, following the previously mentioned method $[18,19]$. Hippocampal tissues were extracted by homogenization using lysis buffer ( $\mathrm{pH}, 7.6)$ After separating $30 \mu \mathrm{g}$ protein using sodium dodecyl sulfate-polyacrylamide gel electrophoresis, the protein was moved to a nitrocellulose membrane (GE Healthcare Bio-Sciences, Pittsburgh, PA, USA). The membrane was treated with $5 \%$ skimmed milk powder (BD Difco, Detroit, MI, USA) for blocking, and incubated with $0.1 \%$ Tween-20 (Sigma Aldrich Co.) for 1 hour at room temperature. The membrane was treated with the primary antibodies such as rabbit anti-VCAM-1 (1:1,000, Cell Signaling Technology), rabbit anti-ICAM-1 (1:1,000, Cell Signaling Technology), mouse anti-TNF- $\alpha$ (1:1,000; Santa Cruz Biotechnology, Santa Cruz, CA, USA), rabbit anti-IL-6 (1:1,000; Santa Cruz Biotechnology), and mouse anti-IL-1 $\beta$ (1:1,000; Santa Cruz Biotechnology). Membranes were subsequently incubated for 1 hour with peroxidase-tagged secondary antibodies. Enhanced chemiluminescence detection kit (DoGen, Seoul, Korea) was used for visualization of protein, and quantitative analysis of bands was calculated using Image-ProPlus program (Media Cybernetics, Rockville, MD, USA).

\section{Statistical Analysis}

IBM SPSS Statistics ver. 26.0 (IBM Co., Armonk, NY, USA) software was used for the analysis of data statistically. One-way analysis of variance and Tukey post hoc test were applied for statistical processing of experimental results. The results were indicated as the mean \pm standard error of the mean and $\mathrm{P}<0.05$ showed statistical significance.

\section{RESULTS}

\section{Lipid Profiles}

Fig. 1 shows lipid profiles. Serum TC, LDL-C, and TG level was increased and serum HDL-C level was decreased in the P407-treated hyperlipidemia rats compared to the normal rats $(\mathrm{P}<0.05)$. Treadmill running decreased serum TC, LDL-C, and TG level and increased serum HDL-C in the P-407-treated hyperlipidemia rats $(\mathrm{P}<0.05)$. Statistical significance was not found between the normal rats and the normal and treadmill exercise rats.

\section{Short-term Memory}

Fig. 2 shows the result of step-down avoidance task. Latency time was decreased in the P-407-treated hyperlipidemia rats compared to the normal rats $(\mathrm{P}<0.05)$. Treadmill running enhanced latency time in the P-407-treated hyperlipidemia rats $(\mathrm{P}<0.05)$. Statistical significance was not found between the normal rats and the normal and treadmill exercise rats. 

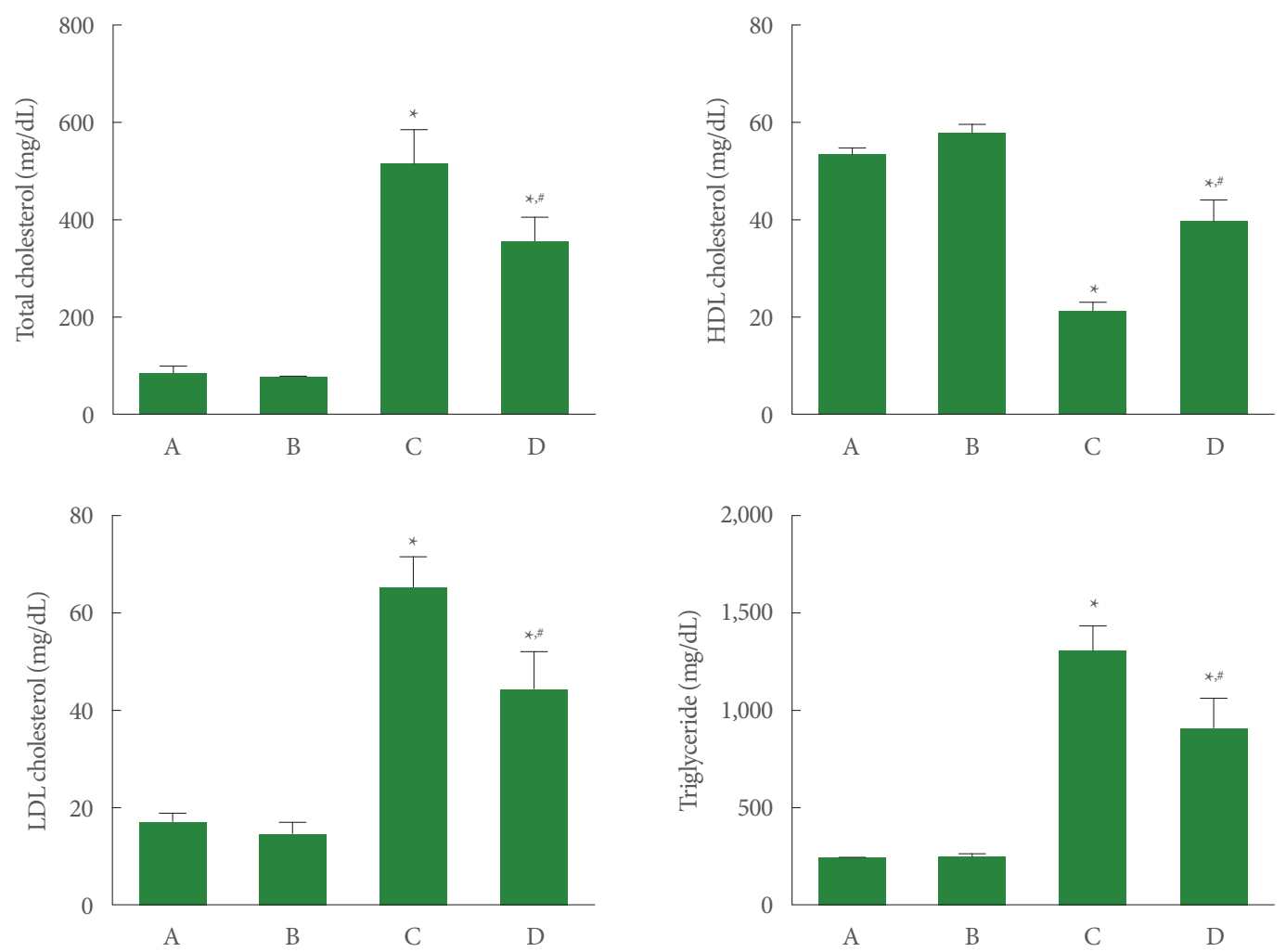

Fig. 1. Lipid profiles. Upper left panel: total cholesterol. Upper right panel: high-density lipoprotein (HDL) cholesterol. Lower left panel: low-density lipoprotein (LDL) cholesterol. Lower right panel: triglyceride. A, normal group; B, normal and treadmill exercise group; C, poloxamer-407-treated group; D, poloxamer-407-treated and treadmill exercise group. ${ }^{*} \mathrm{P}<0.05$ vs. normal rats. ${ }^{*} \mathrm{P}<0.05$ vs. poloxamer-407-treated rats.

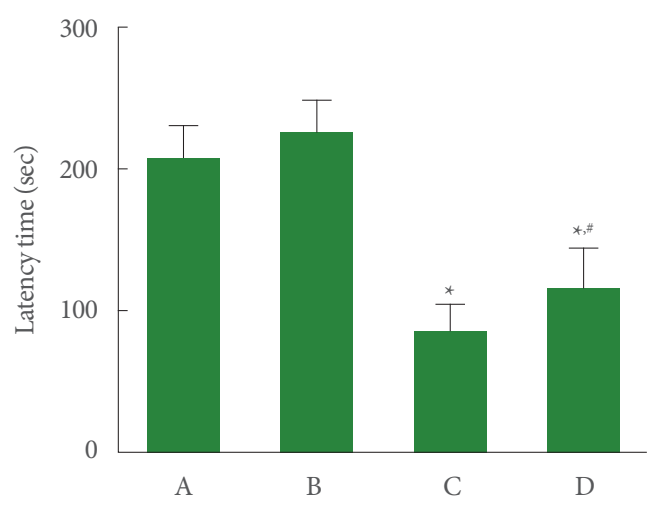

Fig. 2. Step-down avoidance task. A, normal group; B, normal and treadmill exercise group; $\mathrm{C}$, poloxamer-407-treated group; $\mathrm{D}$, poloxamer-407-treated and treadmill exercise group. ${ }^{\star} \mathrm{P}<$ 0.05 vs. normal rats. ${ }^{*} \mathrm{P}<0.05$ vs. poloxamer- 407 -treated rats.

\section{GFAP Expression in Hippocampal Dentate Gyrus}

Fig. 3 shows GFAP expression in the hippocampal dentate gyrus. GFAP expression was increased in the P-407-treated hy- perlipidemia rats compared to the normal rats $(\mathrm{P}<0.05)$. Treadmill running decreased GFAP expression in the P-407-treated hyperlipidemia rats $(\mathrm{P}<0.05)$. Statistical significance was not found between the normal rats and the normal and treadmill exercise rats.

\section{Iba-1 Expression in Hippocampal Dentate Gyrus}

Fig. 4 shows Iba-1 expression in the hippocampal dentate gyrus. Iba- 1 was increased in the $\mathrm{P}-407$-treated hyperlipidemia rats compared to the normal rats $(\mathrm{P}<0.05)$. Treadmill running decreased Iba-1 expression in the P-407-treated hyperlipidemia rats $(\mathrm{P}<0.05)$. Statistical significance was not found between the normal rats and the normal and treadmill exercise rats.

\section{Adhesion Molecules in Hippocampus}

Fig. 5 shows expression of adhesion molecules in the hippocampus. VCAM-1 and ICAM-1 expression was increased in the P-407-treated hyperlipidemia rats compared to the normal rats $(\mathrm{P}<0.05)$. Treadmill running decreased VCAM- 1 and 

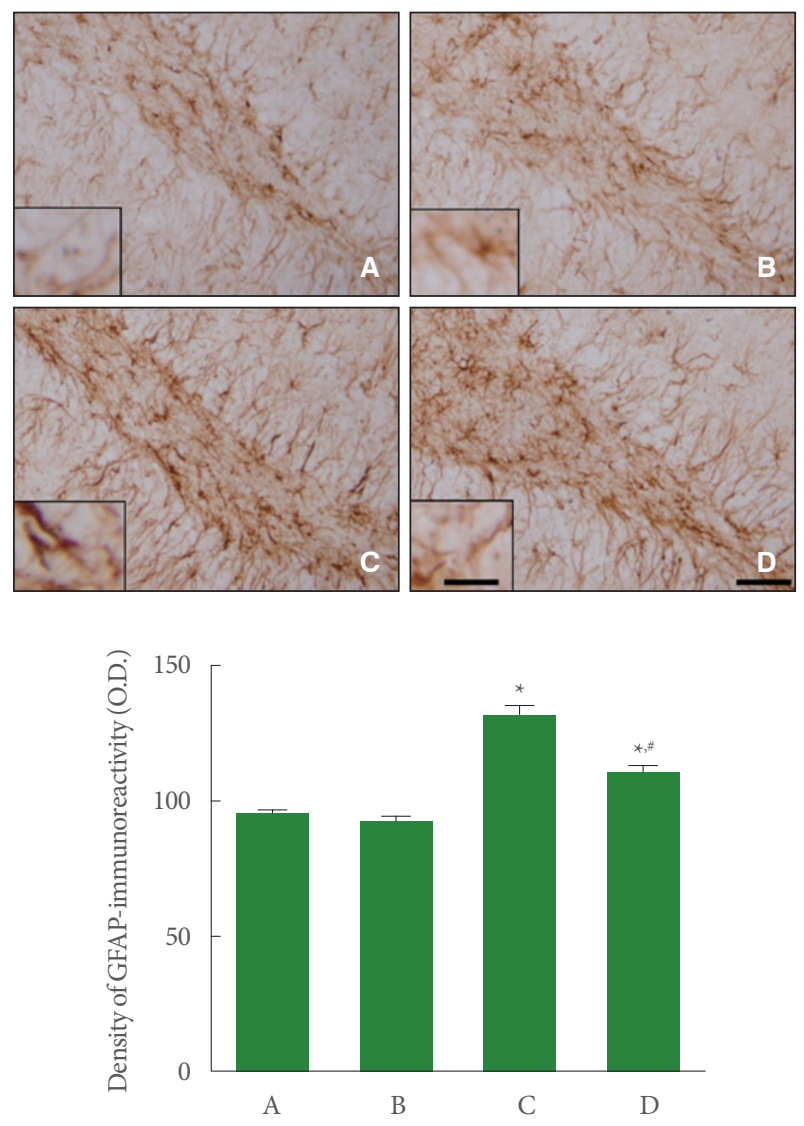

Fig. 3. Glial fibrillary acidic protein (GFAP) expression. Upper panel: photomicrographs of GFAP. Small square scale bar is 200 $\mu \mathrm{m}$ and large square scale bar is $50 \mu \mathrm{m}$. Lower panel: density of GFAP in each group A, normal group; B, normal and treadmill exercise group; $\mathrm{C}$, poloxamer-407-treated group; $\mathrm{D}$, poloxamer407-treated and treadmill exercise group. ${ }^{\star} \mathrm{P}<0.05$ vs. normal rats. ${ }^{*} \mathrm{P}<0.05$ vs. poloxamer- 407 -treated rats.

ICAM-1 expression in the P-407-treated hyperlipidemia rats $(\mathrm{P}<0.05)$. Statistical significance was not found between the normal rats and the normal and treadmill exercise rats.

\section{Proinflammatory Cytokines in Hippocampus}

Fig. 6 shows expression of proinflammatory cytokines in the hippocampus. TNF- $\alpha$, IL- 6 , and IL- $1 \beta$ expression was enhanced in the P-407-treated hyperlipidemia rats compared to the normal rats $(\mathrm{P}<0.05)$. Treadmill running decreased TNF- $\alpha$, IL-6, and IL-1 $\beta$ expression in the P-407-treated hyperlipidemia rats $(\mathrm{P}<0.05)$. Statistical significance was not found between the normal rats and the normal and treadmill exercise rats.
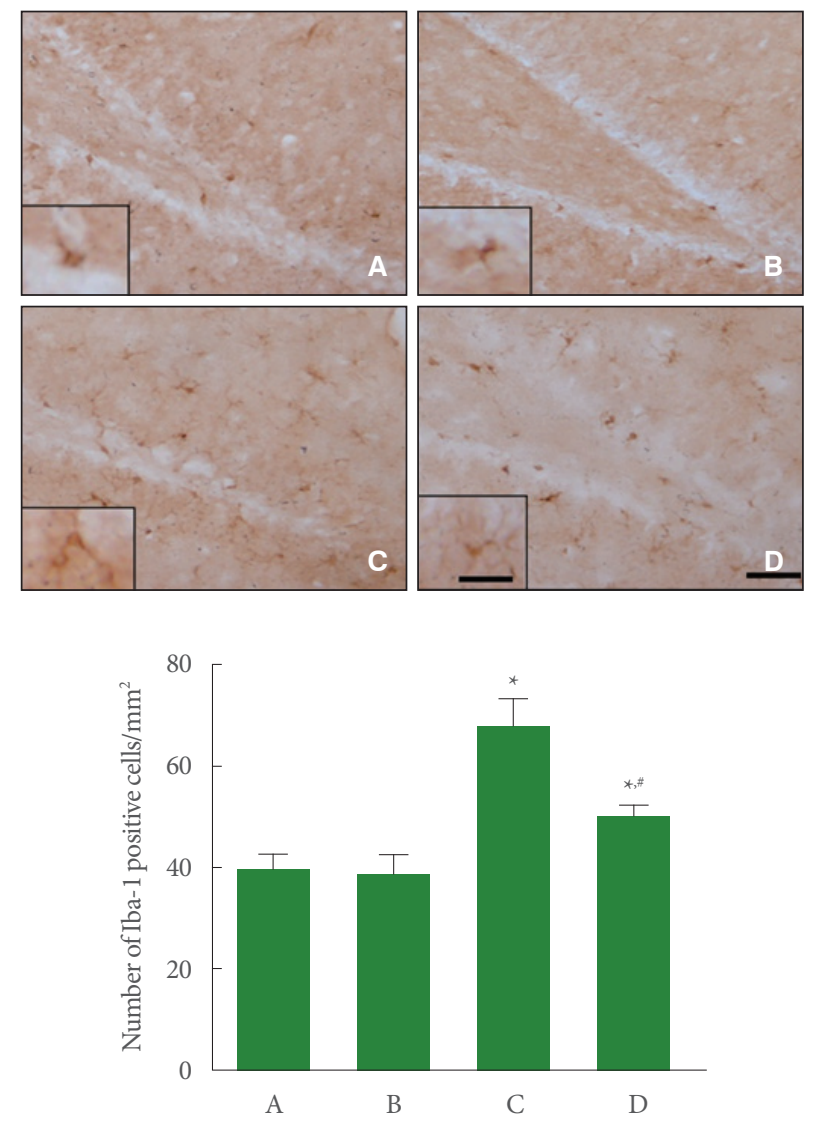

Fig. 4. Ionized calcium binding adaptor molecule 1 (Iba-1). Upper panel: photomicrographs of Iba-1. Small square scale bar is $200 \mu \mathrm{m}$ and large square scale bar is $50 \mu \mathrm{m}$. Lower panel: number of Iba-1 in each group. A, normal group; B, normal and treadmill exercise group; C, poloxamer-407-treated group; D, poloxamer-407-treated and treadmill exercise group. ${ }^{\star} \mathrm{P}<0.05$ vs. normal rats. ${ }^{*} \mathrm{P}<0.05$ vs. poloxamer- 407 -treated rats.

\section{DISCUSSION}

Elevated TC, LDL, and TG level and low HDL-C level are related with an increased risk of atherosclerosis and ischemic stroke [20,21]. P-407 is known to increase LDL-C and TG level and decrease HDL-C level [22]. In the current study, increment in serum TC, LDL-C, and TG level and decrement in serum HDL-C level were observed in the hyperlipidemia rats. Treadmill exercise suppressed serum TC, LDL, and TG level, and enhanced serum HDL-C level in the hyperlipidemia rats. The current results suggest that treadmill running has a preventive effect on hyperlipidemia.

Cholesterol is known to exerts significant effect on synaptic plasticity and brain function, including learning ability and 

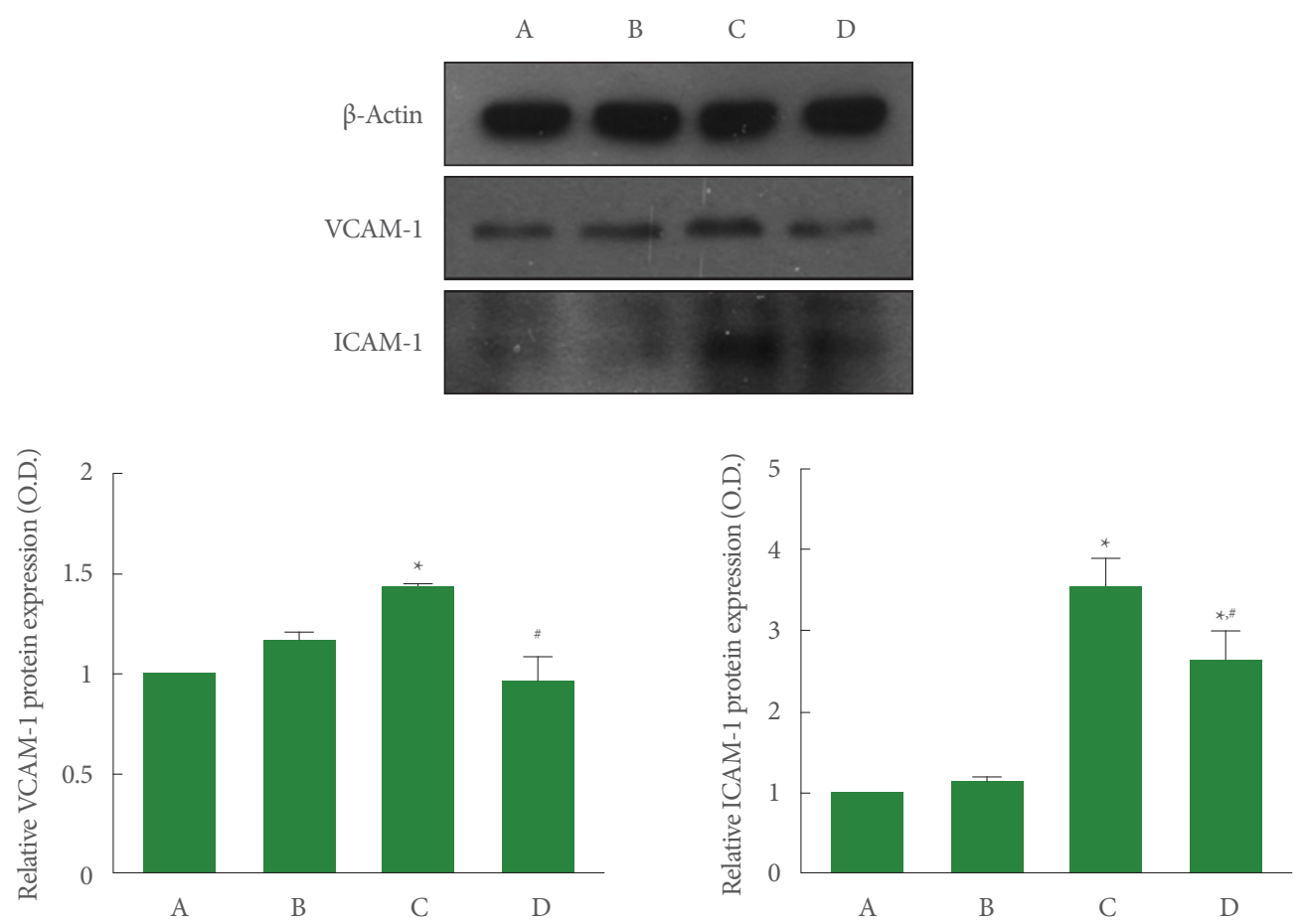

Fig. 5. Adhesion molecules expression. Upper panel: representative expression of vascular cell adhesion molecule (VCAM)-1 and intercellular adhesion molecule (ICAM)-1. Lower left panel: relative VCAM-1 expression in each group. Lower right panel: relative ICAM-1 expression in each group. A, normal group; B, normal and treadmill exercise group; C, poloxamer-407-treated group; D, poloxamer-407-treated and treadmill exercise group. ${ }^{\star} \mathrm{P}<0.05$ vs. normal rats. ${ }^{*} \mathrm{P}<0.05$ vs. poloxamer- 407 -treated rats.

memory process [23]. Previous studies have demonstrated that hyperlipidemia is a inducing factor for the cognitive impairment of Alzheimer disease [24,25]. Hyperlipidemia induced by P-407 administration leads to cognitive impairment [17]. Exercise is one of the important treatments to improve cognitive function including memory ability [15]. In the current study, impairment of short-term memory was observed in the hyperlipidemic rats. Treadmill exercise significantly improved shortterm memory in the hyperlipidemia rats. The current results suggest that treadmill running is effective in alleviating shortterm memory deficits caused by hyperlipidemia.

Reactive astrogliosis and microglial activation has been considered as the hallmark of Alzheimer disease [26]. A high-cholesterol diet induced hippocampal morphological changes, including reactive astrogliosis, increased microglia activation, and decreased neurodevelopment [27,28]. In the current study, enhanced expression of GFAP and Iba-1 was found in the hyperlipidemia rats. Treadmill exercise significantly decreased the expression of GFAP and Iba- 1 in the hyperlipidemic rats. The current results indicate treadmill running inhibits reactive astrogliosis and microglial activation in the hyperlipidemia rats.
The adhesion of vascular endothelium, regulated by many adhesion molecules, including VCAM-1 and ICAM-1, is one of the important mechanisms for the induction of inflammation in atherosclerosis [29]. VCAM-1 and ICAM-1 expression was upregulated by proinflammatory cytokines, such as TNF- $\alpha$, IL6 , and IFN- $\gamma$ [30]. Enhancement of VCAM-1 and ICAM-1 expression was strongly associated with increased incidence of atherosclerosis and Alzheimer's disease [31,32]. Exercise is considered to be one of the basic regulators of cell adhesion molecules [33], and aerobic exercise reduced endothelial activation makers, such as VCAM-1 and ICAM-1, and proinflammatory cytokines, such as TNF- $\alpha$ and IL-6, in old people. In the current study, the expression of VCAM-1 and ICAM-1 was increased with enhanced TNF- $\alpha$, IL- 6 , and IL- $1 \beta$ expression in the hyperlipidemia rats. Treadmill exercise significantly decreased the expression of VCAM-1 and ICAM-1 with suppressed TNF- $\alpha$, IL-6, and IL-1 $\beta$ expression in the hyperlipidemia rats. The current results indicate that treadmill running reduces the expression of adhesion molecules by suppressing proinflammatory cytokines in the hyperlipidemia rats.

In conclusion, treadmill running ameliorated memory defi- 

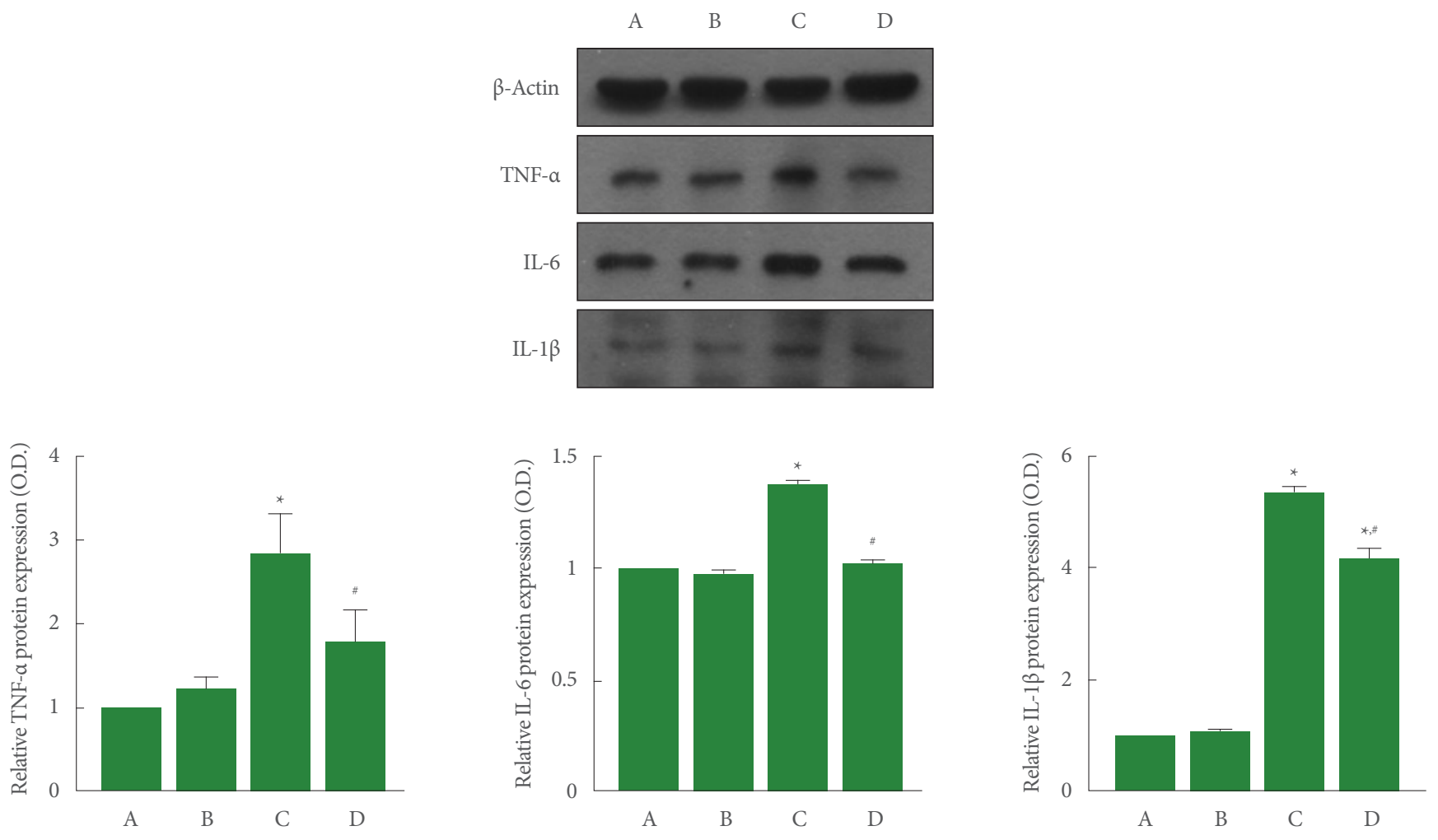

Fig. 6. Proinflammatory cytokines expression. Upper panel: representative expression of tumor necrosis factor (TNF)- $\alpha$, interleukin (IL)-6, and IL-1 $\beta$. Lower left panel: relative TNF- $\alpha$ expression in each group. Lower middle panel: relative IL-6 expression in each group. Lower right panel: relative IL-1 $\beta$ expression in each group. A, normal group; B, normal and treadmill exercise group; $C$, poloxamer-407-treated group; $\mathrm{D}$, poloxamer- 407 -treated and treadmill exercise group. ${ }^{\star} \mathrm{P}<0.05$ vs. normal rats. ${ }^{*} \mathrm{P}<0.05$ vs. poloxamer407-treated rats.

cits by inhibiting hippocampal neuroinflammation in the hyperlipidemia. The current study suggests that treadmill running serves as the treatment strategy for the cognitive dysfunction caused by hyperlipidemia.

\section{AUTHOR CONTRIBUTION STATEMENT}

- Conceptualization: SSP

- Data curation: SSP

- Formal analysis: TWK, YHS, YJP

- Funding acquisition: MSS

- Methodology: $M K K$

- Project administration: MSS

- Visualization: TWK, YHS, YJP

- Writing-original draft: MSS

- Writing-review \& editing: MSS

\section{ORCID}

Sang-Seo Park

0000-0001-7033-9630

Tae-Woon Kim

0000-0001-8832-0874

Yun-Hee Sung

Yun-Jin Park

0000-0002-4877-9784

Myung-Ki Kim

0000-0001-6696-2542

0000-0002-5821-9203

0000-0002-7462-2211

\section{REFERENCES}

1. Nelson RH. Hyperlipidemia as a risk factor for cardiovascular disease. Prim Care 2013;40:195-211.

2. Polidori MC, Pientka L, Mecocci P. A review of the major vascular risk factors related to Alzheimer's disease. J Alzheimers Dis 2012; 32:521-30.

3. Chaudhary HR, Brocks DR. The single dose poloxamer 407 model of hyperlipidemia; systemic effects on lipids assessed using pharma- 
cokinetic methods, and its effects on adipokines. J Pharm Pharm Sci 2013;16:65-73.

4. Maragakis NJ, Rothstein JD. Mechanisms of disease: astrocytes in neurodegenerative disease. Nat Clin Pract Neurol 2006;2:679-89.

5. Schmidt-Kastner R, Szymas J, Hossmann KA. Immunohistochemical study of glial reaction and serum protein extravasation in relation to neuronal damage in rat hippocampus after ischemia. Neuroscience 1990;38:527-40.

6. Boche D, Perry VH, Nicoll JA. Activation patterns of microglia and their identification in the human brain. Neuropathol Appl Neurobiol 2013;39:3-18.

7. Ohsawa K, Imai Y, Sasaki Y, Kohsaka S. Microglia/macrophagespecific protein Ibal binds to fimbrin and enhances its actin-bundling activity. J Neurochem 2004;88:844-56.

8. Drechsler M, Megens RT, van Zandvoort M, Weber C, Soehnlein O. Hyperlipidemia-triggered neutrophilia promotes early atherosclerosis. Circulation 2010;122:1837-45.

9. Fentoğlu O, Kirzioğlu FY, Ozdem M, Koçak, H, Sütçü R, Sert T. Proinflammatory cytokine levels in hyperlipidemic patients with periodontitis after periodontal treatment. Oral Dis 2012;18:299306.

10. Libby P. Inflammation in atherosclerosis. Nature 2002;420:868-74.

11. Jang Y, Lincoff AM, Plow EF, Topol EJ. Cell adhesion molecules in coronary artery disease. J Am Coll Cardiol 1994;24:1591-600.

12. Bigley NJ, Perymon H, Bowman GC, Hull BE, Stills HF, Henderson RA. Inflammatory cytokines and cell adhesion molecules in a rat model of decompression sickness. J Interferon Cytokine Res 2008; 28:55-63.

13. Huang CW, Tsai MH, Chen NC, Chen WH, Lu YT, Lui CC, et al. Clinical significance of circulating vascular cell adhesion molecule-1 to white matter disintegrity in Alzheimer's dementia. Thromb Haemost 2015;114:1230-40.

14. Li S, Kim JY, Sim YJ. Effects of 10-week combined training on lipid metabolic regulatory hormones and metabolic syndrome index according to exercise dose in obese male college students. J Exerc Rehabil 2020;16:101-7.

15. Hong M, Kim M, Kim TW, Park SS, Kim MK, Park YH, et al. Treadmill exercise improves motor function and short-term memory by enhancing synaptic plasticity and neurogenesis in photothrombotic stroke mice. Int Neurourol J 2020;24(Suppl 1):S28-38.

16. Ko YJ, Kim BK, Ji ES. Treadmill exercise in obese maternal rats during pregnancy improves spatial memory through activation of phosphatidylinositol 3-kinase pathway in the hippocampus of rat pups. J Exerc Rehabil 2020;16:483-8.

17. Ruchel JB, Braun JBS, Adefegha SA, Guedes Manzoni A, Abdalla
FH, de Oliveira JS, et al. Guarana (Paullinia cupana) ameliorates memory impairment and modulates acetylcholinesterase activity in Poloxamer-407-induced hyperlipidemia in rat brain. Physiol Behav 2016;168:11-9.

18. Lee SS, Kim CJ, Shin MS, Lim BV. Treadmill exercise ameliorates memory impairment through ERK-Akt-CREB-BDNF signaling pathway in cerebral ischemia gerbils. J Exerc Rehabil 2020;1:49-57.

19. Kim M, Kim TW, Kim CJ, Shin MS, Hong M, Park HS, et al. Berberine ameliorates brain inflammation in poloxamer 407-induced hyperlipidemic rats. Int Neurourol J 2019;23(Suppl 2):S102-10.

20. Carey VJ, Bishop L, Laranjo N, Harshfield BJ, Kwiat C, Sacks FM. Contribution of high plasma triglycerides and low high-density lipoprotein cholesterol to residual risk of coronary heart disease after establishment of low-density lipoprotein cholesterol control. Am J Cardiol 2010;106:757-63.

21. Emerging Risk Factors Collaboration, Di Angelantonio E, Sarwar N, Perry P, Kaptoge S, Ray KK, et al. Major lipids, apolipoproteins, and risk of vascular disease. JAMA 2009;302:1993-2000.

22. Johnston TP. Poloxamer 407 increases soluble adhesion molecules, ICAM-1, VCAM-1 and E-selectin, in C57BL/6 mice. J Pharm Pharmacol 2009;61:1681-8.

23. Schreurs BG. The effects of cholesterol on learning and memory. Neurosci Biobehav Rev 2010;34:1366-79.

24. Loera-Valencia R, Goikolea J, Parrado-Fernandez C, Merino-Serrais $\mathrm{P}$, Maioli S. Alterations in cholesterol metabolism as a risk factor for developing Alzheimer's disease: potential novel targets for treatment. J Steroid Biochem Mol Biol 2019;190:104-14.

25. Cheng Y, Jin Y, Unverzagt FW, Su L, Yang L, Ma F, et al. The relationship between cholesterol and cognitive function is homocysteine-dependent. Clin Interv Aging 2014;9:1823-29.

26. Heneka MT, Carson MJ, El Khoury J, Landreth GE, Brosseron F, Feinstein DL, et al. Neuroinflammation in Alzheimer's disease. Lancet Neurol 2015;14:388-405.

27. de Oliveira J, Engel DF, de Paula GC, Dos Santos DB, Lopes JB, Farina $\mathrm{M}$, et al. High cholesterol diet exacerbates blood-brain barrier disruption in LDLr-/- mice: impact on cognitive function. J Alzheimers Dis 2020;78:97-115.

28. Freeman LR, Small BJ, Bickford PC, Umphlet C, Granholm AC. High-fat/high-cholesterol diet inhibits growth of fetal hippocampal transplants via increased inflammation. Cell Transplant 2011;20: 1499-514.

29. Nakashima Y, Raines EW, Plump AS, Breslow JL, Ross R. Upregulation of VCAM-1 and ICAM-1 at atherosclerosis-prone sites on the endothelium in the ApoE-deficient mouse. Arterioscler Thromb Vasc Biol 1998;18:842-51. 
30. Hosokawa Y, Hosokawa I, Ozaki K, Nakae H, Matsuo T. Cytokines differentially regulate ICAM-1 and VCAM-1 expression on human gingival fibroblasts. Clin Exp Immunol 2006;144:494-502.

31. Cybulsky MI, Gimbrone MA Jr. Endothelial expression of a mononuclear leukocyte adhesion molecule during atherogenesis. Science 1991;251:788-91.

32. Nielsen HM, Londos E, Minthon L, Janciauskiene SM. Soluble adhesion molecules and angiotensin-converting enzyme in dementia.
Neurobiol Dis 2007;26:27-35.

33. Koh Y, Park J. Cell adhesion molecules and exercise. J Inflamm Res 2018;11:297-306.

34. Abd El-Kader SM, Al-Shreef FM, Al-jiffri OH. Impact of aerobic exercise versus resisted exercise on endothelial activation markers and inflammatory cytokines among elderly. Afr Health Sci 2019;19: 2874-80. 